\title{
Importância e fatores intervenientes na representatividade, democratização e tomada de decisão nos conselhos superiores de institutos federais de educação ${ }^{1}$
}

Importance and intervening factors in representativeness, democratization, and decision-making process in the deliberative councils of federal institutes of education

Importancia y factores intervinientes en la representatividad, democratización y toma de decisiones en los consejos superiores de los institutos federales de educación

\author{
MARCOS VINICIUS CAMPELO JUNIOR \\ http://orcid.org/0000-0001-6501-644X \\ Universidade Federal de Mato Grosso do Sul \\ Programa de Pós-graduação em Ensino de Ciências \\ Departamento de Educação \\ Campo Grande, MS, Brasil \\ ÉRISON FERREIRA MENDONÇA FILHO \\ http://orcid.org/0000-0002-1163-4194 \\ Universidade Federal de Goiás \\ Programa de Pós-graduação em Administração Pública \\ Departamento de Administração \\ Inhumas, GO, Brasil \\ JONAS DE PAULA OLIVEIRA \\ http://orcid.org/0000-0002-2592-7350 \\ Universidade Federal de Mato Grosso do Sul \\ Programa de Pós-graduação em Ensino de Ciências \\ Departamento de Educação \\ Campo Grande, MS, Brasil \\ SUZETE ROSANA DE CASTRO WIZIAC \\ http://orcid.org/0000-0003-2269-603X \\ Universidade Federal de Mato Grosso do Sul \\ Programa de Pós-graduação em Ensino de Ciências \\ Departamento de Educação \\ Campo Grande, MS, Brasil
}

1 Este artigo é composto de parte de dados e reflexões desenvolvidas na Dissertação de Mestrado apresentada por Érison Ferreira Mendonça Filho ao Programa de Pós-Graduação em Administração Pública da Universidade Federal de Goiás no ano de 2016, com o título "Fatores Intervenientes na Tomada de Decisão em Conselhos Superiores dos Institutos Federais de Educação”. 
Resumo: Este artigo analisa a representatividade, os fatores intervenientes no processo de tomada de decisão dos conselhos superiores dos Institutos Federais de Educação, Ciência e Tecnologia (IFs) e a potencialidade desses órgãos colegiados para a democratização institucional. Com o aporte teórico dos estudos sobre Modelos Racionais de tomada de decisão, o texto apresenta uma investigação de natureza qualitativa que se dividiu entre pesquisa documental e pesquisa de campo. Constatou-se um elevado índice de representatividade nos conselhos, embora ainda sejam necessários aprimoramentos na disponibilização de informações aos seus membros, na comunicação entre eles e a comunidade institucional e nas técnicas de deliberação.

Palavras-chave: Representatividade; Conselhos Superiores; Institutos Federais de Educação.

\begin{abstract}
This article analyzes the representativeness, the factors involved in the decisionmaking process of the higher councils of the Federal Institutes of Education, Science and Technology (FIs), and the potential of these collegiate bodies for institutional democratization. With the theoretical contribution of studies on Rational Models of decision-making, the text presents a qualitative investigation divided between documentary research and field research. There was a high level of representativeness on the boards, although improvements are still needed in making information available to its members, in communication between them and the institutional community, and in the deliberation techniques.
\end{abstract}

Keywords: Representativeness; Superior Councils; Federal Institutes of Education.

Resumen: Este articulo analiza la representatividad, los factores que intervienen en el proceso de toma de decisiones de los consejos superiores de los Institutos Federales de Educación, Ciencia y Tecnologia (IFs) y el potencial de estos órganos colegiados para la democratización institucional. Con el aporte teórico de estudios sobre Modelos Racionales de toma de decisiones, el texto presenta una investigación cualitativa que se dividió entre investigación documental e investigación de campo. Hubo un alto nivel de representatividad en los directorios, aunque aún se requieren mejoras en la puesta a disposición de sus miembros, en la comunicación entre ellos y la comunidad institucional y en las técnicas de deliberación.

Palabras clave: Representatividad; Consejos superiores; Institutos Federales de Educación.

\title{
INTRODUÇÃO
}

$\mathrm{Na}$ sociedade em geral, as pessoas desejam ter suas demandas e aspirações ouvidas e, de alguma forma, aspiram contribuir com a definição de diretrizes e políticas institucionais. Por isso, embora seja possível a delegação da responsabilidade da tomada de decisão por meio da escolha de representantes, as pessoas não se contentam mais em aguardar o próximo pleito para terem suas vozes ouvidas nas políticas públicas que afetam suas vidas. 
Quando se analisam as experiências democráticas em diversos países constata-se, por exemplo, que a vontade dos eleitores não necessariamente se reflete nas decisões de seus representantes. $\mathrm{O}$ que se tem como consequência é um desalento das sociedades quanto à democracia representativa, algo que se expressa no número de abstenções dos eleitores em votações em diversos países (GHIRARDI; CUNHA, 2013).

Nas escolas públicas, essas experiências democráticas estão ameaçadas principalmente em países que possuem um sistema democrático frágil como o Brasil que, a partir da sua última eleição presidencial de 2018, passou a gerar entraves para as garantias, direitos e liberdades construídas em um período de 30 anos, após a aprovação da Constituição Federal de 1988 (AFONSO, 2020).

Nessa esteira, com o sentido de suprir as lacunas presentes no processo de decisão baseado em eleições, surgem as experiências de participação contínua da sociedade na tomada de decisão, por meio de órgãos colegiados como os conselhos consultivos e deliberativos, também chamados de conselhos gestores ou setoriais que são instrumentos de uma gestão democrática.

A expressão 'gestão democrática' é usada na Constituição de 1988 - Art. 206 - VI, para evidenciar a necessidade de "gestão democrática do ensino público, na forma da lei” (BRASIL, 1988), e de acordo com Nardi e Boiago (2018), essa expressão se tornou uma corrente de pesquisa no ambiente acadêmico.

As reflexões sobre as experiências de gestão democrática permitem que seus aspectos positivos sejam referendados e os negativos sejam revistos e aprimorados. Dessa forma, interessa saber como a gestão compartilhada aplicada por meio dos conselhos criados nos IFs vem sendo realizada, pois em decorrência das potencialidades e das dissonâncias observadas entre as propostas dos colegiados e os resultados obtidos nas decisões de seus representantes no sistema político-administrativo, considera-se o tema da representação política e da tomada de decisão nesses conselhos muito relevantes.

Além disso, muitos processos democráticos que foram implantados no Brasil com a Constituição Federal de 1988, atualmente encontram-se ameaçados diante de ataques, mudanças e extinção de experiências. O Governo Bolsonaro tem realizado medidas de cortes e alteração de composição nas mais diversas áreas de políticas públicas, alterando assim, conselhos e processos de gestão participativa que se encontravam em pleno trabalho. Uma das justificativas apresentadas é a da associação entre os conselhos e os governos progressistas, ignorando totalmente o canal de comunicação com a sociedade. 
Diante dessa situação, a reflexão sobre os conselhos das instituições públicas apresenta-se como um tema atual e urgente para ser debatido. Neste trabalho, o interesse é o de conhecer e analisar os modelos e aplicações presentes nos conselhos dos IFs, que foram implantados a partir de 2008.

Nos IFs, a gestão democrática que é prevista por meio dos conselhos superiores - de ensino, pesquisa e extensão, e de campi - busca tornar estas instituições mais eficazes na execução das políticas públicas de educação, mais voltadas aos interesses da comunidade, mais transparentes quanto ao processo deliberativo e mais eficazes na coordenação dos serviços públicos.

No entanto, considera-se o fato de que a simples existência de conselhos não é capaz de promover uma maior responsabilização política dos gestores públicos, ou de garantir uma redução no número de irregularidades, ou na má gestão das políticas públicas (SANTANA, 2011). Logo, ressalta-se a ideia de que a expansão quantitativa dos conselhos gestores não significa, necessariamente, seu sucesso diante dos desafios a eles interpostos (GOMES, 2003). E no que concerne aos aspectos qualitativos do tema, destaca-se a importância de compreender as deficiências quanto à representatividade dos conselheiros e quanto à capacidade destes de deliberar e impor as decisões acordadas (TEIXEIRA, 2000).

Diferentemente das universidades federais que, por sua vez, têm a representatividade nos conselhos superiores prevista na Lei de Diretrizes e Bases (1996), a qual é de 70\% para docentes, os Institutos Federais de Educação, Ciência e Tecnologia (IFs), criados por meio da lei $\mathrm{n}^{\circ} 11.862$, não limitaram o percentual de representatividade dos segmentos que devem compor o conselho superior, assegurando a presença da comunidade acadêmica no processo decisório. Esse modelo, teoricamente, é um avanço na democratização da gestão dessas instituições, já que possibilita a sua estruturação com maior igualdade e distribuição participativa de poder, pois de acordo com Luiz e Barcelli (2013) a distribuição de poder nos conselhos fortalece o espaço democrático e favorece que as ações da gestão se efetivem.

Nesse sentido, o texto visa: discutir o formato organizacional e o papel de gestão participativa dos conselhos superiores; os fatores intervenientes no processo decisório nesses conselhos gestores; e a importância dessa experiência no âmbito dos processos democráticos.

Os dados da investigação foram coletados na pesquisa de mestrado de Mendonça Filho (2016), cujo processo se dividiu em pesquisa documental e a pesquisa de campo, ambas com abordagem qualitativa. A coleta documental foi realizada por meio do acesso aos Regimentos Gerais e Estatutos dos IFs brasileiros, todos disponíveis nas páginas oficiais dessas instituições na internet. A análise dos conteúdos, segundo Tozoni (2009, p. 45), visou "desvendar os 
sentidos aparentes ou ocultos de um texto, um documento, um discurso ou qualquer outro tipo de comunicação". No que se refere à coleta de dados junto aos atores participantes de conselhos foram aplicados questionários via Google Forms, com escala de mensuração multi-item no formato Likert. Nesta proposta, de acordo com Cummins e Gullone (2000), quando uma pessoa responde a uma escala de mensuração do tipo Likert, conforme a proposta de Cummins e Gullone (2000), aplicado em 14 instituições das 5 regiões brasileiras, cujo resultado é uma consequência da combinação da direção da resposta (concordo ou não concordo) com a intensidade da resposta (extensão do concordar e não concordar), as intensidades de concordância ou discordância se apresentaram aos respondentes de maneira a: concorda totalmente, parcialmente, não concorda e nem discorda, discorda parcialmente, discorda totalmente (Alexandre et al., 2003)

A seguir, estão apresentados os dados e a reflexão sobre o tema, cuja exposição está organizada com os seguintes tópicos: Conselhos Gestores, Atores do Processo Decisório, Modelos de tomada de decisão, Os Conselhos dos IFs e, por fim, Resultados e a análise da situação da representatividade dos conselhos superiores dos IFs, destacando aspectos que podem ser repensados com vistas a melhorar a democratização e a eficiência no processo decisório desses conselhos, sobretudo no atual momento político brasileiro.

\section{OS CONSELHOS GESTORES E OS ATORES SEUS PROCESSOS}

Segundo o regulamento do IFNMG/Almenara (2015), Conselho Gestor é um órgão consultivo e deliberativo e de assessoramento à Direção-Geral, naquelas matérias de interesse exclusivo da Unidade de Ensino e integrante da estrutura administrativa básica do Campus. Tem por finalidade colaborar para o aperfeiçoamento dos processos educativo, administrativo e orçamentáriofinanceiro e de zelar pela correta execução das políticas de gestão no Campus.

Para Carneiro (2002), os conselhos são espaços públicos que possibilitam a representação de interesses coletivos na cena política e na definição de agenda pública, sendo ao mesmo tempo, por seu caráter híbrido, parte do Estado e da sociedade. Sua estrutura é legalmente definida e institucionalizada e sua razão de existência reside na ação conjunta ao aparato estatal para a elaboração e gestão de políticas sociais.

Desse modo, de acordo com Gohn (2001), os conselhos gestores são novos instrumentos de expressão, representação e participação que possuem potencial de transformação política e são organizados de forma descentralizada. Constam em seus objetivos viabilizar a participação de segmentos sociais na 
formulação de políticas públicas e possibilitar à população, o acesso aos espaços, que eram exclusivamente dedicados a uma minoria que detinha o poder de tomar decisões.

A importância dos conselhos reside no fato de que, muitas vezes, as decisões são tomadas por um indivíduo isolado, seja governador, ministro, presidente, reitor, diretor ou gerente. Por outro lado, a decisão pode ainda caber a um ou vários colegiados e não apenas a um indivíduo (PRÈVE; MORITZ; DE OLIVEIRA, 2010).

Nesses casos, observa-se que os atores, na prática, influenciam o processo decisório por meio das relações que estabelecem entre si, na forma de alianças: quando os interesses são parecidos; ou de conflitos: quando os valores se opõem (PRÈVE; MORITZ; DE OLIVEIRA, 2010).

Outra forma de influência dos atores do processo decisório é a autoridade, que se vale da persuasão e da anuência de seus subordinados. A autoridade pode dar ênfase a um aspecto de arbitrariedade, em contraponto a um espaço totalmente democrático (BALESTRIN, 2002).

Nesse segmento, é importante ressaltar a importância da negociação, processo no qual a decisão mútua é feita com a concordância das partes. Essa decisão é conseguida com a busca do consenso (GOMES; GOMES, 2000).

Os decisores costumam incorporar suas características pessoais ao processo de tomada de decisão, no entanto, a diferença básica entre os decisores reside no fato de que alguns utilizam os componentes de sua personalidade, de seus valores, de sua experiência e de suas opiniões para que a decisão possa atender os objetivos propostos. Independentemente do ator, seja indivíduo ou colegiado, é exigido do decisor competência analítica, rapidez na ação e foco no problema a ser resolvido. Alguns traços em comum influenciam o desempenho de um líder, dentre os quais pode-se destacar: consciência, energia, inteligência, domínio, autocontrole, sociabilidade, abertura a experiências, conhecimento da relevância das tarefas e a estabilidade emocional (PRÈVE; MORITZ; DE OLIVEIRA, 2010).

Ademais, além de personalidade, dos valores e das características pessoais, é imprescindível que os decisores trabalhem com ações articuladoras com os membros da equipe gestora em meio aos processos administrativos e pedagógicos (BERNARDO; BORDE; CERQUEIRA, 2018). 


\section{MODELOS DE TOMADA DE DECISÃO}

A modelagem teórica de processos decisórios preconiza que a tomada de decisão seja racional, de maneira que os gestores façam escolhas consistentes, mesmo com as restrições impostas. Para Robbins e Decenzo (2004), um tomador de decisões, para ser racional, deve ser plenamente objetivo e lógico. Por outro lado, afirmam que "as suposições de racionalidade não são sempre aplicáveis porque o nível de certeza pelo modelo racional raramente existe" (ROBBINS; DECENZO, 2004, p. 81).

Apesar de a racionalidade considerar que os indivíduos sejam objetivos e lógicos, Bazerman (2004) aponta que muitas vezes faltam, aos tomadores de decisões, as informações necessárias à resolução de um dado problema. A qualidade e quantidade das informações disponíveis estão restritas, por exemplo, a recursos ligados ao armazenamento e à disponibilidade de informações. Além disso, existem limitações de percepções que também restringem a capacidade dos tomadores de decisões de encontrarem a melhor solução diante das opções disponíveis (SANTOS; WAGNER, 2007).

Ao modelo racional de tomada de decisão são associados diversos modelos. No modelo Clássico, por exemplo, são enfatizados os procedimentos lógico-formais do processo decisório, sendo por isso um modelo normativo que define como o tomador de decisões deve fazê-lo (DAFT, 2002). O Administrativo é outro exemplo de modelo, que descreve como os gestores realmente tomam decisões em situações complexas em vez de dizer como eles deveriam tomar decisões a partir de uma determinada teoria ideal. Neste modelo, entende-se que a racionalidade é limitada, considerando-se que existem limitações humanas e ambientais que interferem na tomada de decisão. Assim, o que se busca é uma decisão satisfatória diante das possibilidades (PRÈVE; MORITZ; DE OLIVEIRA, 2010).

Contudo, são também essenciais para o entendimento do processo de decisão em conselhos gestores de instituições os modelos comportamentalista e normativo. No comportamentalista, entende-se que o comportamento dos indivíduos em organizações é acentuado e abrangente. Nele, os gestores devem procurar prever esses comportamentos durante as decisões para se evitar situações desagradáveis em seu contexto. No modelo normativo, a maneira como deve transcorrer o processo decisório é a preocupação central. Este é o modelo de grupos-técnicos profissionais ou colegiados (PRÈVE; MORITZ; DE OLIVEIRA, 2010). 
Existem outros modelos específicos apresentados para a tomada de decisão. Vahl (1991), por exemplo, sugere que as universidades possuam um sistema no qual os membros decisores possam optar e decidir por alternativas mais ou menos racionais, uma vez que a administração de uma universidade envolve decisões sobre seus objetivos básicos e sua missão.

De acordo com Prève, Moritz e de Oliveira (2010), o processo decisório nestas instituições de ensino deve ser analisado sob a perspectiva dos modelos administrativo, comportamentalista e normativo da tomada de decisão.

Prève, Moritz e de Oliveira (2010, p. 87) ainda descrevem que, frequentemente, há uma relação entre os vários modelos de tomada de decisão e o contexto em que ela ocorre, como a estrutura, a cultura e o ambiente organizacional, de acordo com o modelo de gestão adotado: social ou societal. Dessa forma, os autores apresentam os seguintes fatores abaixo descritos como sendo os principais a serem considerados:

\footnotetext{
Ambiente: apresenta complexidade, é dinâmico e hostil;

Organização: distribuição do poder, tipo de organização (autocracia, burocracia) e tipo de cultura (de poder, de papéis, de pessoas e de tarefas);

Característica do decisor: proativo, intuitivo, reativo, analítico, autônomo, inovador e disposto a correr riscos;

Tipos de assunto: complexos, urgentes, simples, abrangentes e dinâmicos. (PRÈVE; MORITZ; DE OLIVEIRA, 2010, p. 87).
}

Portanto, de forma geral, os autores reafirmam a necessidade dos modelos de tomada de decisão para que os gestores possam compreender a estrutura organizacional, as relações presentes em suas instituições e a eficácia das decisões tomadas. Com isso, torna-se também essencial a investigação de modelos e processos como os dos IFs, conforme descreveremos a seguir.

\section{OS CONSELHOS GESTORES DOS INSTITUTOS FEDERAIS}

Os IFs são instituições federais vinculadas ao Ministério da Educação, criadas pela Lei $n^{\circ} 11.892$, de 29 de dezembro de 2008. Possuem natureza jurídica de autarquias, sendo detentoras de autonomia administrativa, patrimonial, financeira, didático-pedagógica e disciplinar. Para efeito da incidência das disposições que regem a regulação, avaliação e supervisão da instituição e dos cursos de educação superior, os IFs são equiparados às universidades federais.

A Lei $n^{0}$ 11.892/2008, que instituiu a Rede Federal de Educação Profissional, Científica e Tecnológica, estabeleceu, como seu escopo, que a gestão dos IFs tenha como órgãos superiores o Colégio de Dirigentes e o Conselho Superior (BRASIL, 2008). 
Os Conselhos Superiores têm caráter consultivo e deliberativo e a composição mais comumente estabelecida possui representantes dos docentes, dos estudantes, dos técnicos-administrativos, dos egressos da instituição, da sociedade civil, do Ministério da Educação e do Colégio de Dirigentes do respectivo IF, assegurada a representação paritária dos segmentos que compõem a unidade acadêmica (BRASIL, 2008).

Os Conselhos Superiores dos IFs são responsáveis por aprovar as diretrizes de cada IF e zelar pela política educacional estabelecida pelo Ministério da Educação; autorizar a criação, alteração curricular e extinção de cursos no âmbito da instituição; aprovar a estrutura administrativa e o Regimento Geral da instituição; deliberar sobre questões submetidas sob sua apreciação como, por exemplo, aprovar o projeto político pedagógico, a organização didática, os regulamentos e normas internas dos cursos, o plano de desenvolvimento institucional, a proposta orçamentária anual, dentre outros.

Ressalta-se, mais uma vez, a importância dada à representatividade e ao processo de tomada de decisão nos conselhos superiores dos IFs, já que estes são instâncias máximas de poder dessas instituições educacionais distribuídas por todo o território brasileiro.

\section{A COMPOSIÇÃO E A REPRESENTAÇÃO PREVISTAS NOS CONSELHOS SUPERIORES DOS IFS}

Na amostra obtida na investigação, na perspectiva de Gil (2008), chegouse a 14 instituições das 5 regiões brasileiras, a saber: IFBaiano, IFC, IFFarroupilha, IFG, IFGoiano, IFMT, IFMG, IFRR, IFRS, IFPI, IFSul, IFSuldeMinas, IFTM e IFTO. Dos 531 conselheiros contactados, obteve-se respostas de 122 deles nos questionários, portanto, uma taxa de resposta de 23,94\%. Verificou-se que, dos 38 IFs existentes, 31 dos seus Conselhos Superiores (82\%) possuíam a mesma estrutura administrativa no que se refere à composição de seus membros. Os sete restantes (18\%) apresentam composições diversas, principalmente, quantitativamente e, em alguns casos, qualitativamente.

Foram considerados dois grupos de conselhos. O primeiro é o grupo de Conselhos Superiores Típicos (CSTs) e o segundo o de Conselhos Superiores Atípicos (CSAs). Suas composições estão descritas no quadro a seguir: 


\section{Quadro 2 - Composição dos Conselhos Superiores dos Institutos Federais Brasileiros}

\begin{tabular}{|c|c|}
\hline Conselhos Superiores & Composição \\
\hline \multirow{8}{*}{ Típicos } & Reitor como presidente; \\
\hline & 05 (cinco) representantes docentes; \\
\hline & 05 (cinco) representantes discentes; \\
\hline & 05 (cinco) representantes técnico-administrativos; \\
\hline & 02 (dois) representantes dos egressos; \\
\hline & 06 (seis) representantes da sociedade civil; \\
\hline & 01 (um) representante do Ministério da Educação; \\
\hline & 05 (cinco) diretores-gerais de campi. \\
\hline \multirow{12}{*}{ Atípicos } & Reitor como presidente; \\
\hline & 01 (um) por campus ou 04 (quatro) ou 08 (oito) representantes docentes; \\
\hline & 01 (um) ou 01 (um) por campus ou 04 (quatro) representantes discentes; \\
\hline & 01 (um) ou 01 (um) por campus ou 04 (quatro) representantes técnico-administrativos; \\
\hline & 01 (um) representante dos egressos; \\
\hline & 03 (três) ou 04 (quatro) ou 09 (nove) ou 14 (catorze) representantes da sociedade civil; \\
\hline & 01 (um) representante do Ministério da Educação; \\
\hline & 01 (um) por campus ou 03 (três) diretores-gerais de campi. \\
\hline & 01 (um) ou 04 (quatro) ou 05 (cinco) pró-reitores; \\
\hline & 01 (um) representante de seção sindical; \\
\hline & 01 (um) representante dos servidores aposentados; \\
\hline & Último ex-reitor. \\
\hline
\end{tabular}

Fonte: Adaptado de Mendonça Filho (2020).

Nos CSTs, a representação paritária de alunos, professores, técnicosadministrativos e representantes do Colégio de Dirigentes (entidade formada por diretores-gerais dos campi), se apresentou na proporção de $1 / 3$ do número total de campi para cada categoria, com o mínimo de dois e o máximo de cinco representantes; dois representantes de egressos indicados pelas entidades representativas dos profissionais formados; seis representantes da sociedade civil, sendo dois indicados por entidades patronais, dois por entidades de trabalhadores e dois do setor público ou empresas estatais, designados pela Secretaria de Educação Profissional e Tecnológica; um representante do Ministério da Educação, designado pela Secretaria de Educação Profissional e Tecnológica; e o reitor como membro nato e presidente do conselho, encerrando um total de 30 membros. 
Os CSAs, por sua vez, apresentaram composições que variam, em número de membros virtuais, de 16 até 73. Destacam-se nas duas pontas o IFSertão-PE e IFRS.

No IFSertão-PE não se identificou representação paritária entre docentes, discentes e técnico-administrativos, de maneira que apenas um discente e um técnico-administrativo estão representados em comparação a oito docentes. Há também uma representação menor da sociedade civil, já que há apenas três representantes em detrimento da média de seis encontrados em outros IFs.

No IFRS chegou-se à representação de um docente, um discente e um técnico administrativo por campus, além de todos os diretores-gerais dos campi. Considerando-se que os campi estabelecidos e os em processo de implantação deste IF somam 17 unidades, já se contam 68 membros, além dos demais representantes previstos em seu estatuto.

No Conselho Superior do IFAC, verificou-se uma maior representação da sociedade civil com a presença de 14 membros. Também merece destaque nos CSAs do IFAC, IFMS e IFPR a previsão da participação de Pró-Reitores, variando em número de um a cinco membros.

Ainda, com relação à atipicidade dos conselhos superiores, encontrou-se a presença de 1 representante de seção sindical no IFBaiano e de 1 representante de servidores aposentados no IFPE.

\section{PERFIL DOS MEMBROS CONSELHEIROS DOS IFS}

Da amostra identificada, a quantidade e o segmento ao qual pertencem os respondentes estão discriminados no Gráfico 1: 


\section{Gráfico 1 - Segmento da comunidade a que pertencem os respondentes}

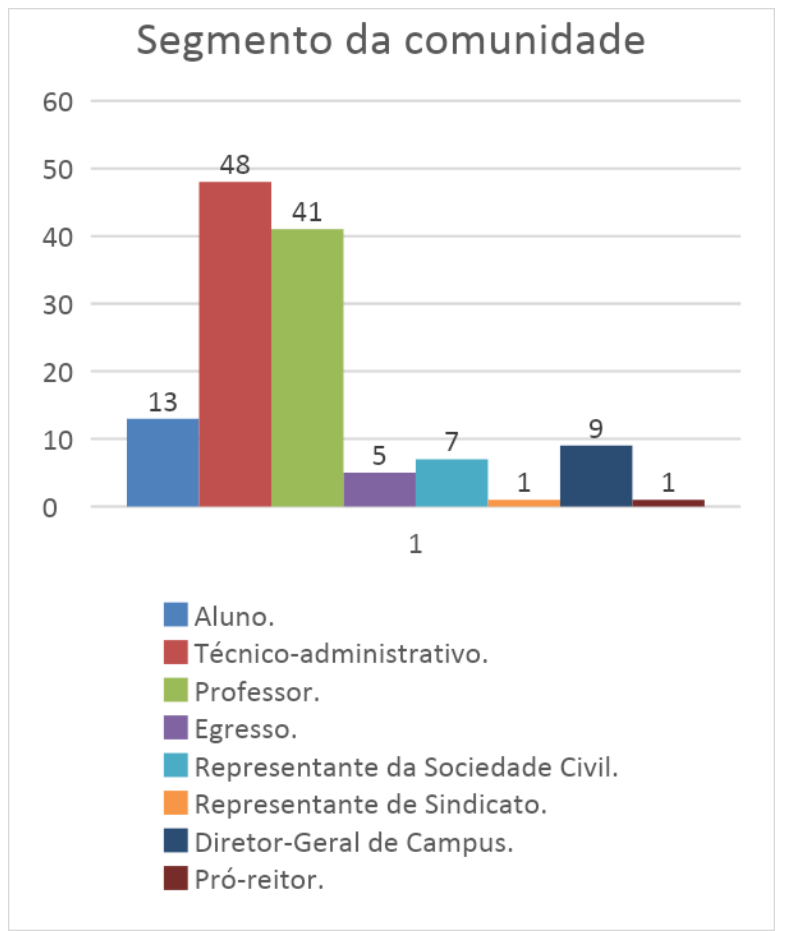

Fonte: Mendonça Filho (2016).

Entre os participantes da pesquisa, os técnicos administrativos e docentes foram os dois segmentos que mais responderam aos questionários. Destaca-se que os diretores-gerais de Campus e Pró-reitor, geralmente, são docentes e em alguns casos técnicos administrativos. A maior parte dos respondentes $(69,05 \%)$ afirmou já ter participado de atividades representativas em outras instituições antes de serem membros de conselho superior. Desses, 17,24\% informaram que sua experiência pregressa era de até um ano, $41,38 \%$ informaram que era de um a três anos e os outros $41,38 \%$ atuaram em outras atividades participativas por mais de 5 anos.

Os grêmios, centros ou diretórios acadêmicos foram as instituições mais citadas como experiência anterior dos participantes $(21,12 \%)$, seguidos pelos sindicatos $(17,39 \%)$, associações $(14,91 \%)$, órgãos de classe profissional e outras instituições $(11,18 \%$ cada), partidos políticos $(8,7 \%)$, instituições religiosas $(8,07 \%)$, outras instituições de ensino $(6,21 \%)$ e fóruns $(1,24 \%)$. 


\section{ESTRUTURA ORGANIZACIONAL E REPRESENTATIVIDADE DOS CONSELHOS DOS IFS}

Ao analisar os resultados das respostas obtidas, constata-se que a maioria dos respondentes $(54,76 \%)$ concordou totalmente que, independentemente, do que reza seu estatuto ou regimento geral, seu conselho superior tem a representação de todos aqueles que são impactados por suas decisões, e 42,06\% dos conselheiros consideram que a proporção existente de cada segmento da comunidade acadêmica nos conselhos é representativa. Aproximadamente 5\% discordam totalmente da existência de representatividade.

Aproximadamente $30 \%$ dos respondentes concordam totalmente que a estrutura organizacional e atribuições dos conselhos superiores são satisfatórias às demandas da comunidade e $53,97 \%$ dos respondentes concordaram parcialmente. Considerando-se os critérios utilizados para a avaliação dos resultados dos questionários da escala de Likert, a não concordância total implica que os fundamentos da assertiva apresentada se aplicam em sua maioria, mas não em sua totalidade.

\section{FORMAS DE LIDERANÇA E DE AUTORIDADE SEGUNDO OS CONSELHEIROS DOS IFS}

Considerando-se o exposto, $42,86 \%$ dos conselheiros discordaram totalmente que a autoridade hierárquica era um fator de influência em sua tomada de decisão e, aproximadamente, 10\%, discordam parcialmente sobre a influência das autoridades em sua tomada decisão. Por outro lado, aproximadamente $20 \%$ dos conselheiros concordaram parcialmente que há uma influência da autoridade hierárquica na sua tomada de decisão e $8 \%$ concordaram totalmente com essa influência. Isso indica que o formato e a dinâmica das reuniões concedem liberdade à maior parte dos conselheiros para defenderem seus pontos de vista sem a existência de qualquer tipo de constrangimento ou influência impostos pela administração. Porém, há um grupo relevante de conselheiros que aponta que pode ocorrer a influência de autoridade hierárquica nas tomadas de decisões, enquanto um grupo pequeno de conselheiros percebem que as decisões são influenciadas por essas autoridades. Ou seja, tem-se efetivamente nos conselhos superiores dos IFs um espaço entre iguais que permite a independência para a liberdade decisória, mas também há situações em que as autoridades hierárquicas interferem na liberdade decisória dos conselheiros. 
Na mesma direção, 33,31\% dos respondentes discordaram totalmente e, aproximadamente, $15 \%$ parcialmente discordaram da assertiva que dizia que as estratégias de trabalho e os valores pessoais de outros membros influenciavam a sua tomada de decisão, enquanto o grupo de respondentes que concordam parcialmente ou totalmente com a existência da influência de outros membros são aproximadamente $40 \%$. Assim como, 50,79\% rejeitaram totalmente a afirmação de que os componentes de personalidade (como carisma e simpatia) de outros membros são fatores determinantes para a sua tomada de decisão.

Houve a concordância parcial de $57,14 \%$ sobre a existência de um membro que monopolize as discussões por ter mais conhecimentos sobre determinado assunto. A formação prévia em gestão e liderança, por sua vez, foi considerada parcialmente determinante para a atuação como líder nos Conselhos Superiores para $35,71 \%$ dos conselheiros e como totalmente determinante por aproximadamente $29 \%$ dos respondentes.

\section{O ACESSO ÀS INFORMAÇÕES E O PROCESSO DE COMUNICAÇÃO PRESENTE NOS CONSELHOS DOS IFS}

No que concerne às informações necessárias para fazer um julgamento, $40,48 \%$ dos respondentes concordaram parcialmente e, aproximadamente, $34 \%$ concordam totalmente com a assertiva de que todas as informações necessárias para uma tomada de decisão consciente e racional estavam disponíveis e acessíveis aos conselheiros; enquanto $42,06 \%$ concordaram parcialmente e $40 \%$ concordam totalmente que essas informações eram confiáveis.

A maioria dos respondentes (66\%) concordaram parcialmente que fontes primárias de informações, como leis ou resoluções, são mais utilizadas do que as fontes secundárias, como relatórios feitos pela própria administração ou pelos membros do próprio conselho. Por um lado, essa atitude pode fazer com que se dependa mais tempo para que cada membro análise todos os materiais necessários à sua tomada de decisão, já que a existência de relatórios poderia ressaltar as informações mais importantes ou relevantes de um determinado documento. Os membros representados em 59\% concordaram parcialmente que as condições de risco e incerteza eram levadas em consideração, quando nem todas as informações necessárias estavam disponíveis para solucionar um problema complexo, o que revela a utilização do modelo administrativo de tomada de decisão. Ainda, com relação às informações, 53\% dos respondentes concordaram parcialmente e, aproximadamente, $30 \%$ concordam totalmente com a assertiva de que, quando 
nem todas as informações estavam disponíveis ou acessíveis, as escolhas eram feitas a partir da experiência ou da intuição e, apenas, aproximadamente 5\% dos respondentes discordaram totalmente dessa assertiva.

No processo de comunicação, considerando-se que a eficácia da comunicação é indispensável para a transmissão de informações necessárias à tomada de decisão, 47,62\% dos respondentes concordaram parcialmente e, aproximadamente, $20 \%$ concordam totalmente que tanto a comunicação entre diferentes níveis hierárquicos (verticais) quanto entre os mesmos níveis hierárquicos (horizontais) é satisfatória; 42,96\% dos respondentes concordaram totalmente e $37,04 \%$ concordam parcialmente que a comunicação entre os conselheiros sempre se dava de forma cordial; 53,17\% dos conselheiros concordaram parcialmente e aproximadamente $32 \%$ concordaram totalmente que os membros do Conselho Superior se expressavam de maneira clara e inteligível.

Dessa forma, 41,27\% dos conselheiros concordaram totalmente e, aproximadamente, $40 \%$ concordam parcialmente que a tecnologia da informação era utilizada para melhorar o processo de comunicação entre os membros do conselho e, apenas, aproximadamente 4\% discordam totalmente dessa assertiva.

Diferentemente, $42,06 \%$ concordaram parcialmente e, aproximadamente, $18 \%$ concordam totalmente que todas as pessoas impactadas pelas decisões do conselho eram comunicadas de maneira eficaz sobre as decisões.

\section{PLANEJAMENTO E CARACTERÍSTICAS DAS REUNIÕES DOS IFS}

Quanto às metodologias utilizadas no planejamento das reuniões para o processo deliberativo, 38,39\% dos conselheiros concordaram parcialmente e, aproximadamente, $11 \%$ concordam totalmente que era feita a previsão de cenários utópico, realista e de crise, para se tomar a melhor decisão quando o impacto de uma escolha não era imediato e, aproximadamente, 11\% discordam totalmente dessa assertiva.

Quanto aos tipos de problemas a serem discutidos pelos Conselhos Superiores, 44,44\% concordaram parcialmente que as decisões se voltavam mais à resolução de problemas imediatos. Esse mesmo percentual de respondentes concordou parcialmente e $10 \%$ concordaram totalmente que a maioria das decisões eram destinadas a resolver problemas abrangentes e complexos e, apenas, 1\% discordou totalmente dessa assertiva. Ou seja, de acordo com os respondentes, grande parte dos problemas a se resolver é imediato, abrangente e complexo. 
Conselheiros representados em 43,65\% concordaram parcialmente que as reuniões têm foco e pautas definidas, de maneira que não se perde a objetividade durante o processo de tomada de decisão. Como outros $42,86 \%$ dos respondentes concordaram totalmente com essa assertiva, considera-se que a objetividade das reuniões seja satisfatória.

Com relação aos métodos de tomada de decisão, 38,89\% concordaram parcialmente e, aproximadamente, $14 \%$ concordam totalmente que eram utilizadas metodologias e ferramentas científicas e técnicas específicas para a tomada de decisão.

\section{PROCESSO DE TOMADA DE DECISÃO SEGUNDO OS CONSELHEIROS DOS IFS}

Os conselheiros foram questionados se mediante às dificuldades do processo decisório havia o trabalho em equipe fora das reuniões dos conselhos e $42,06 \%$ dos respondentes concordaram parcialmente e, aproximadamente, $31 \%$ concordam totalmente com essa assertiva.

Ao serem questionados sobre o convite a especialistas para auxiliar a tomada de decisão em temas complexos, $35,71 \%$ concordaram parcialmente e, aproximadamente, $28 \%$ concordaram totalmente com essa assertiva.

Questionou-se aos conselheiros se recursos tecnológicos (como videoconferência, compartilhamento de dados em nuvem, dentre outros) eram utilizados para melhorar o processo de tomada de decisão, e 38,10\% dos respondentes concordaram parcialmente e aproximadamente $27 \%$ concordam totalmente com essa assertiva.

Além disso, questionou-se aos conselheiros se era utilizado o método de tomada de decisão racional durante o processo deliberativo, qual seja, de forma sintética: 1) examinar a situação; 2) criar alternativas; 3) avaliar as alternativas e escolher a melhor; e 4) implementar e monitorar a decisão. 36,51\% dos conselheiros concordaram parcialmente e $20 \%$ concordaram totalmente com essa assertiva.

Percebe-se que não há concordância majoritária dos conselheiros sobre a necessidade de especialistas e de recursos tecnológicos nos processos de tomada de decisão racional. Portanto, a decisão racional não é considerada sistematicamente no processo deliberativo dos conselheiros. Tais aspectos permitem inferir que, embora com boa representatividade, os conselhos dos IFS necessitam rever os fatores que intervêm nos processos de decisão, inclusive os voltados para a infraestrutura de apoio, conforme se discute a seguir. 


\section{REPRESENTATIVIDADE, FATORES INTERVENIENTES NO PROCESSO DE TOMADA DE DECISÃO À POTENCIALIDADE DOS CONSELHOS SUPERIORES DOS IFS}

Vimos com os dados da pesquisa que os Conselhos Superiores dos IFS, embora heterogêneos em sua estrutura organizacional, possuem um elevado índice de representatividade com relação às partes interessadas e impactadas em suas decisões, embora, quando observamos os números totais uma prevalência de representação dos docentes, tendo em vista que as vagas destinadas ao reitor e diretores-gerais, geralmente são ocupadas por essa categoria. No entanto, constatou-se que o método de tomada de decisão racional não é plenamente aplicado nos conselhos superiores. Dessa maneira, mesmo considerado o formato típico de constituição dos conselhos como um avanço na democratização do processo decisório das IFs, compreendemos que a implementação de um processo de deliberação sistemático para tomada de decisões operacionais ou rotineiras nos conselhos reduziria a influência de autoridades hierárquicas e auxiliaria os decisores a alcançar melhores resultados com base na racionalidade.

Além disso, pode-se verificar que a composição com 30 membros seja a majoritária, no entanto, não foi possível determinar se esta seria a quantidade ideal ou recomendada de conselheiros, já que não se esteve presente nas reuniões dos diversos conselhos para se analisar a dinâmica interna de funcionamento de cada um e compará-los. Sugere-se trabalhos que aprofundem a avaliação in loco dos conselhos.

Diante da maioria dos problemas identificados nos Conselhos dos IFs, indica-se a utilização de ferramentas e técnicas científicas que facilitem a tomada de decisão, assim como a utilização de recursos tecnológicos, tais como videoconferência, compartilhamento de dados em nuvem e bancos de dados eletrônicos para otimizar e agilizar o acesso às informações necessárias ao processo decisório.

Diante de tudo isso, conforme explicitado por Demo (1993), a participação nunca está acabada, podendo, por esta razão, ser ampliada e aprimorada. Considera-se, de acordo com Tenório e Kronemberger (2016, p. 18), que a "participação é um processo de conquista não somente na ótica da comunidade ou dos interessados, mas também do técnico, do professor, do pesquisador, do intelectual" e é parte do cotidiano dos indivíduos, sendo instrumento de exercício da cidadania e apropriação de direitos para a construção de um destino social e democrático. 
A gestão democrática tem um papel estrutural muito importante no aprimoramento das instituições de ensino e segundo Bernardo, Borde e Cerqueira (2018), a construção coletiva de um colegiado envolve a participação de todos. Para Magalhães (2019), a existência de uma assimetria, entre os conselhos superiores, proporciona uma melhor conexão entre os diversos atores envolvidos, contribuindo para os trabalhos prestados à sociedade. O autor também ressalta que os temas "participação" e "governança" estão sempre em destaque na administração pública e, a partir das eleições de 2018, essa demanda aumentou, destacando a necessidade de uma participação mais ampla da sociedade.

Após as eleições de 2018, a gestão democrática exercida pelos conselhos superiores dos IFs vem sofrendo intervenções do governo federal e vários reitores eleitos em processo de consulta realizadas nos IFs não foram nomeados. Esses fatos colocam em risco o avanço da democratização na gestão desses conselhos, considerando que as decisões tomadas pela comunidade não estão sendo respeitadas como ocorreu no IFRN e no IFSC (SINASEFE, 2020). A primeira iniciativa, com a MP No 914 de 24 de dezembro de 2019, foi estabelecer o fim da paridade de votos entre docentes, técnicos e alunos para a escolha de reitores, mas essa escolha ainda deveria ser aprovada pelo conselho. Em 2020, outro ato do governo federal por meio da MP N ${ }^{\circ}$ 979, de 10 junho de 2020, retira dos IFs e dos seus conselhos a prerrogativa de escolherem os seus dirigentes. No caso específico do IFSP, o Conselho Superior (Consup) se manifestou com o processo de intervenção, relatando que:

Até $1^{\circ}$ de junho de 2020, estávamos sob vigência da MP 914, publicada em 24 de dezembro de 2019, que acabava com a paridade dos votos de docentes, técnico-administrativos e alunos, extinguia a eleição de diretores-gerais e criava a lista tríplice para reitor. Era um escárnio, um ataque à democracia, afronta à autonomia universitária e nítida intervenção nos IFs. (NOTA, 2020, s/p).

Mesmo com a publicação da MP No 979/2020, o Consup do IFSP se opõe ao argumento do governo federal de que a medida visava garantir uma consulta democrática e destaca a autonomia do Consup IFSP para iniciar e aprovar um processo eleitoral de escolha de reitor com a participação da comunidade, de forma a executar um processo "justo, transparente, seguro e representativo" (NOTA, 2020, s/p).

Por mais que essas medidas de interferência na atuação dos conselhos superiores dos IFs sejam delimitadas como emergenciais e apenas no período de duração da pandemia decorrente da COVID19, o atual momento já representa um grave retrocesso na eficiência da atuação desses conselhos, tendo em vista que 
os poderes de decisão embasados na representatividade dos envolvidos e com o uso dos melhores recursos de informação e metodologias de gestão não estão sendo respeitados.

\section{CONSIDERAÇÕES FINAIS}

O aprimoramento do modelo estrutural e dos métodos empregados durante a tomada de decisão em conselhos superiores de instituições de ensino superior públicas é o principal aspecto a ser apontado como demanda para a gestão dos Conselhos dos IFs de forma a permitir o aumento da eficiência do processo de tomada de decisão e da obtenção dos resultados mais eficazes possíveis diante da racionalidade limitada e da estrutura de representatividade existente.

Embora tenham sido identificados alguns problemas presentes nos conselhos dos IFs, à experiência presente nesses recentes conselhos incorporaram novos processos de gestão democrática pós Constituição Federal de 1988. Tal experiência precisa ser divulgada, considerando que o formato típico dos conselhos das IFs indica um processo de democratização da gestão destas instituições, tendo em vista que a representatividade constatada indica que há uma proporcionalidade entre as categorias interessadas nas decisões, ou seja, docentes, técnicos, alunos; representantes da administração central como reitores, pró-reitores, diretores de campus e servidores do MEC, além de representantes de sindicatos e da sociedade civil.

No formato atípico, os conselhos não seguem a mesma proporcionalidade entre as categorias interessadas, mas todas as categorias interessadas estão representadas. Verifica-se que a estrutura organizacional adotada nestes conselhos superiores vem contribuindo para a melhoria do processo de tomada de decisão, de modo que, as reuniões em geral estão ocorrendo de forma objetiva e com uma pauta bem definida, por meio de uma comunicação eficaz e cordial entre os conselheiros.

A continuidade do aperfeiçoamento da gestão democrática pode ser constatada na autonomia das decisões que a maior parte dos conselheiros observa, considerando que não são influenciados por autoridades hierárquicas ou por outros membros do conselho. Destaca-se como limitações deste processo o fato de haver discussões que são monopolizadas por membros do conselho que possuem mais conhecimento sobre o assunto, como também, a necessidade de ampliar o uso de técnicas e metodologias adequadas para subsidiar as tomadas de decisão. 
Nestes últimos anos de regime democrático no país, apesar das limitações apontadas, constata-se um aperfeiçoamento da representatividade e das técnicas de tomadas de decisões nos Conselhos Superiores das IFs. No entanto, esse progresso está ameaçado desde 2019, pelo governo Bolsonaro, que usa sua prerrogativa constitucional de emitir Medidas Provisórias para interferir na autonomia da gestão dos IFs e, assim, impossibilitar tomadas de decisões representativas.

À vista disso, as questões técnicas que visam melhoraro processo de tomada de decisões nos conselhos superiores estão diretamente vinculadas à necessidade de ações que visem garantir a participação representativa e democrática nestes conselhos dos IFs. Ressalta-se que este modelo de prática de gestão democrática observado nos IFs não representa as práticas de gestão educacional realizadas nas escolas de ensino básico brasileiras, mas podem ser tomadas como exemplos que visam democratizar a gestão escolar. Por fim, no momento, é necessário lutar para manter e ampliar o uso dos Conselhos Superiores dos IFs como um espaço de gestão democrática, mantendo o foco na necessidade de aperfeiçoar as técnicas científicas que aumentam a eficiência no processo de tomada de decisão.

\section{REFERÊNCIAS}

AFONSO, A. J. Estado, políticas e gestão da educação: resistência ativa para uma agenda democrática com justiça social. Revista Brasileira de Política e Administração da Educação, v. 36, n. 2, p. 403 - 428, mai./ago. 2020.

ALEXANDRE, J. W. C. et al. Análise do Número de Categorias da Escala de Likert Aplicada à Gestão pela Qualidade Total Através da Teoria de Resposta ao Item. Encontro Nacional de Engenharia de Produção, vol. 23, n. 2003, p. $1-8,2003$.

BALESTRIN, A. Uma Análise da Contribuição de Herbert Simon para as Teorias Organizacionais. Revista Eletrônica de Administração, Edição 28, 8 (4), 2002.

BAZERman, M. H. Processo Decisório para Cursos de Administração, Economia e MBAs. Rio de Janeiro: Elsevier, 2004. 
BERNARDO, E. S.; BORDE, A. M.; CERQUEIRA, L. M. Gestão Escolar e Democratização da Escola: desafios e possibilidades de uma construção coletiva. Revista on-line de Política e Gestão Educacional, v. 22, n. esp.1, p. 31-48, 2018. e-ISSN: 1519-9029. Disponível em: < https://periodicos.fclar.unesp.br/ rpge/article/view/10782>. Acesso em: 10 de ago. 2020.

BRASIL. Constituição da República Federativa do Brasil, 1988. Brasília, DF: Senado Federal, 1988.

. Presidência da República. Lei no 11.892, de 29 de dezembro de 2008. Brasília, Distrito Federal, 2008. Disponível em: < http://www.planalto.gov.br/ ccivil_03/_ato2007-2010/2008/lei/111892.htm>. Acesso em: 05 jan. 2020.

.. Medida Provisória No 914, de 24 de dezembro de 2019. Dispõe sobre o processo de escolha dos dirigentes das universidades federais, dos institutos federais e do Colégio Pedro II. Brasília, DF, 2019.

.. Medida Provisória Nº 979, de 10 de junho de 2020. Dispõe sobre a designação de dirigentes pro tempore para as instituições federais de ensino. Brasília, DF, 2020.

CARNeIRO, C. B. L. Conselhos de Políticas Públicas: desafios para sua institucionalização. Revista de Administração Pública, Rio de Janeiro, 36 (2), 277-292, 2002.

CUMMINS, R. A.; GULLONE, E. Why we should not use 5-point Likert scales: the case for subjective quality of life measurement. In: Proceedings, Second International Conference on Quality of Life in Cities, p. 93. Singapore, 2000.

DAFT, R. L. Organizações: teoria e projetos. São Paulo: Pioneira, 2002.

DEMO, P. Participação é uma conquista: noções de política social participativa. $2^{a}$ ed. São Paulo: Cortez, 1993.

GHIRARDI, J. G.; CUNHA, L. G. O Voto de Silêncio: abstenção eleitoral, representações de cidadania. Revista Direito Mackenzie, v. 6, n. 1, p. 160-169, 2013. 
GIL, A. C. Métodos e Técnicas de Pesquisa Social. $6^{a}$ Edição. São Paulo: Atlas S.A, 2008.

GOHN, M. da G. Conselhos Gestores e Participação Sociopolítica. São Paulo: Cortez, 2001.

GOMES, E. G. M. Conselhos Gestores de Políticas Públicas: democracia, controle social e instituições. (dissertação de mestrado), Fundação Getúlio Vargas, São Paulo, 2003.

GOMES, L. F. A. M.; GOMES, C. F. S. Tomada de decisão gerencial: enfoque multicritério. Editora Atlas SA, 2000.

IFNMG. Almenara. Regulamento Interno do Conselho Gestor dos Campi do IFNMG. Reitoria, 2015. Disponível em: < https://www.ifnmg.edu.br/docsregulamentos>. Acesso em: 07 de jul. 2020.

LUIZ, M. C; BARCELLI, J. C. Conselhos escolares e participação: a perspectiva de técnicos de secretarias municipais de educação do Estado de São Paulo. Revista on line de Política e Gestão Educacional, Araraquara, SP, v. 2, n.14, p.1-17, set. 2013.

MAGALHÃES, N. O papel dos conselhos superiores em uma instituição federal de ensino: o caso da Universidade Federal do Estado do Rio de Janeiro - UNIRIO. (dissertação de mestrado), Universidade Federal do Estado do Rio de Janeiro, 2019.

MENDONÇA FILHO, E. F. Fatores Intervenientes na Tomada de Decisão em Conselhos Superiores dos Institutos Federais de Educação. (dissertação de mestrado), Programa de Pós-Graduação em Administração Pública, UFG, Aparecida de Goiânia - GO, 2016.

NARDI, E. L; BOIAGO, P. F. S. Contornos da produção acadêmica sobre gestão democrática do ensino público em teses e dissertações da área da educação (19962015). Revista Brasileira de Política e Administração da Educação, v. 34, n. 3, p. 749-773, set./dez. 2018. 
NOTA da Presidência do Conselho Superior. Instituto Federal de São Paulo, 2020. Disponível em: <https://www.ifsp.edu.br/noticias/1533-nota-dapresidencia-do-conselho-superior>. Acesso em: 07 set. 2020.

PRÉVE, A. D.; MORITZ, G. D. O.; PEREIRA, M. F. Organização, processos e tomada de decisão. Florianópolis, SC: Departamento de Ciências da Administração/UFSC, 2010.

ROBBINS, S. P.; DECENZO, D. A. Fundamentos de Administração: conceitos e aplicações. São Paulo: Prentice Hall, 2004.

SANTANA, V. L. S. Controle Social e Desempenho na Gestão Pública: uma análise dos conselhos locais de educação e saúde. Revista de Políticas Públicas e Gestão Governamental, 10 (1), 2011.

SANTOS, L. P.; WAGNER, R. Processo decisório e tomada de decisão: um dualismo. Simpósio de Excelência em Gestão e Tecnologia, 1-15, 2007.

SINASEFE rechaça nomeações imorais no IFRN e IFSC. Sindicato Nacional dos Servidores Federais da Educação Básica, Profissional e Tecnológica (SINASEFE), 2020. Disponível em: < https://sinasefe.org.br/site/nao-aintervencao-do-mec-no-ifrn-e-no-ifsc/>. Acesso em: 07 set. 2020.

TEIXEIRA, E. C. Efetividade e eficácia dos Conselhos. In: Carvalho, M. C. A. A., \& Teixeira, A. C. C. (Orgs.). Conselhos Gestores de Políticas Públicas. São Paulo: Pólis, 2000.

TENÓRIO, F. G; KRONEMBERGER, T. S. (org). Gestão Social e Conselhos Gestores. Rio de Janeiro: Editora FGV, 2016.

TOZONI-REIS, M. F. C. Metodologia da Pesquisa. 2. Ed. Curitiba: IESDE Brasil S.A, 2009.

VAHL, T. R. Estrutura e gerenciamento das universidades brasileiras. Temas de Administração Universitária. Florianópolis: UFSC, 1991. 


\section{Érison Ferreira Mendonça Filho}

Mestre em Administração Pública pela Universidade Federal de Goiás, Técnico Administrativo do Instituto Federal de Goiás, campi Inhumas-GO. E-mail: erisonmendonca@gmail.com

\section{Marcos Vinicius Campelo Junior}

Doutorando do Programa de Pós-graduação em Ensino de Ciências, Universidade Federal de Mato Grosso do Sul, Campo Grande-MS. E-mail: campelogeografia@gmail.com

\section{Jonas De Paula Oliveira}

Doutorando do Programa de Pós-graduação em Ensino de Ciências, Universidade Federal de Mato Grosso do Sul, Campo Grande-MS. E-mail: jonasdep@gmail. com

\section{Suzete Rosana De Castro Wiziack}

Professora Doutora do Programa de Pós-graduação em Ensino de Ciências, Universidade Federal de Mato Grosso do Sul, Campo Grande-MS. E-mail: suzetew@gmail.com 